\title{
Preimplantation Genetic Testing for Aneuploidies Improve the Clinical Pregnancy Outcome of Patients With AZFc Microdeletion
}

\author{
xiliang wang \\ China Medical University https://orcid.org/0000-0003-2195-181X \\ Yankun Wang \\ peking medriv academy of genetics and reproduction \\ kaibo hou \\ General Hospital of Northern Theatre command \\ dongmei hao \\ General Hospital of Northern Theatre command \\ jinyan zhang \\ General Hospital of Northern Theatre command \\ chang tang \\ General Hospital of Northern Theatre command \\ wei wei \\ General Hospital of Northern Theatre command \\ jia fei ( $\sim$ feijia@jabrehoo.com ) \\ peking medriv academy of genetics and reproduction \\ yuexin yu \\ General Hospital of Northern Theatre command
}

\section{Short report}

Keywords: AZFc microdeletion, ICSI, PGT-A

Posted Date: April 20th, 2021

DOI: https://doi.org/10.21203/rs.3.rs-366595/v1

License: @ (1) This work is licensed under a Creative Commons Attribution 4.0 International License. Read Full License 


\section{Abstract}

\section{Background}

Microdeletions of AZF are the most common factor causing male infertility except Klinefelter syndrome. AZF patients are able to father babies through intracytoplasmic sperm injection (ICSI) and in vitro fertilization (IVF), and the ICSI embryos for IVF can be scored based on morphological criteria. However, the clinical pregnancy rate and the live birth rate are unsatisfactory.

\section{Results}

Here, we investigated the outcomes of using preimplantation genetic testing for aneuploidies (PGT-A) in families with AZFc microdeletions. A total of 26 intracytoplasmic sperm injection (ICSI) cycles were performed in 22 families, 25 ICSI cycles were performed, and 81 embryos underwent PGT-A. Among them, 48 were euploid embryos ( 23 females and 25 males), 30 were aneuploid embryos, and three embryos did not meet the quality control standards. Thirteen ICSI cycles with female euploid embryos and one ICSI cycle with male euploid embryos entered the stage of embryo implantation. Finally, the clinical pregnancy rate was $100 \%(14 / 14)$, and the live birth rate was $85.7 \%(12 / 14)$.

\section{Conclusion}

Compared with other published results, PGT-A increased the chance of fertility in AZFc microdeletion patients.

\section{Background}

Azoospermia factor (AZF) is a region located on the long arm of the $Y$ chromosome (Yq11), including the subgroups AZFa, AZFb and AZFc. Microdeletions of AZF are the most common factor causing male infertility except Klinefelter syndrome, and AZFc microdeletion has the highest frequency, accounting for approximately $80 \%$ of all AZF microdeletions [1]. It is generally believed that patients diagnosed with AZFc microdeletion have residual spermatogenesis ability, and AZFc microdeletion patients can become fathers through intracytoplasmic sperm injection (ICSI) [2-4].

Generally, the embryos obtained by ICSI were scored based on morphological criteria [5], and the best embryos were selected for transfer [6]. However, it has been reported that ICSI possesses higher aneuploidy rates than conventional IVF procedures [7-9]. Moreover, the fertilization rate and embryo quality of AZF microdeletion patients were significantly decreased after ICSI [10,11]. Therefore, when AZFc microdeletion patients receive ICSI, we should pay greater attention to the embryos for transfer. Preimplantation genetic testing for aneuploidy (PGT-A) could exclude aneuploid embryos, enable clinicians to select euploid embryos for embryo transfer, and improve the pregnancy rate and live birth rate [12].

The use of PGT-A in AZFc microdeletion patients has not been reported. Here, this study summarized the clinical outcomes of oligospermia patients diagnosed with AZFc microdeletion who received PGT-A before embryo transfer in our centre (Department of Reproductive Medicine, General Hospital of Northern Theater Command) in recent years. We found that the application of PGT-A improved the pregnancy rate and live birth rate compared to conventional ICSI methods.

\section{Results}

Among 22 couples, the men were 27-43 years old, and the women were 26-38 years old. Twenty-six ICSI cycles were carried out, of which 19 couples conducted one ICSI cycle, two couples conducted two ICSI cycles, and one couple conducted three ICSI cycles. A total of 248 fertilized oocytes were obtained from the 26 ICSI cycles, and 81 blastocysts from 25 cycles were detected by PGT-A. Among the blastocysts detected, 23 (28.4\%) were female euploid blastocysts, 25 (30.9\%) were male euploid blastocysts, 30 (37.0\%) were aneuploid blastocysts, and the remaining 3 (3.7\%) blastocysts failed to pass the quality control after genome amplification (Table 1). 
Table 1

Statistics of 22 couples accepting ICSI and PGT-A cycles. (the table was placed at the end of the document)

\begin{tabular}{|c|c|c|c|c|c|c|c|c|c|c|c|c|}
\hline Family & Cycle & $\begin{array}{l}\text { Date of } \\
\text { consultation }\end{array}$ & $\begin{array}{l}\text { Age of } \\
\text { wife \& } \\
\text { husband }\end{array}$ & $\begin{array}{l}\text { Sperm } \\
\text { concentration } \\
\left(\times 10^{6} / \mathrm{mL}\right)\end{array}$ & $\begin{array}{l}\text { Fertilized } \\
\text { oocytes }\end{array}$ & $\begin{array}{l}\text { Blastocyst } \\
\text { biopsies }\end{array}$ & $\begin{array}{l}\text { Female } \\
\text { euploid }\end{array}$ & $\begin{array}{l}\text { Male } \\
\text { euploid }\end{array}$ & $\begin{array}{l}\text { Implantation } \\
\text { date }\end{array}$ & $\begin{array}{l}\text { Clinical } \\
\text { pregnancy }\end{array}$ & $\begin{array}{l}\text { Early } \\
\text { abortion }\end{array}$ & $\mathrm{Li}$ \\
\hline 1 & 1 & $2015 / 1 / 5$ & $37 \& 37$ & 0.001 & 4 & 1 & 1 & 0 & $2015 / 4 / 13$ & $\sqrt{ }$ & $x$ & $\sqrt{ }$ \\
\hline 2 & 2 & $2015 / 3 / 13$ & $33 \& 35$ & 0.1 & 22 & 2 & 1 & 1 & $2015 / 6 / 30$ & $\sqrt{ }$ & $x$ & $\sqrt{ }$ \\
\hline 3 & 3 & $2015 / 9 / 25$ & $28 \& 33$ & 0.1 & 5 & 1 & 1 & 0 & $2015 / 11 / 25$ & $\sqrt{ }$ & $x$ & $\sqrt{ }$ \\
\hline 4 & 4 & $2015 / 11 / 23$ & $33 \& 32$ & 1 & 7 & 1 & 1 & 0 & $2016 / 5 / 15$ & $\sqrt{ }$ & $\sqrt{ }$ & $x$ \\
\hline 5 & 5 & $2015 / 12 / 1$ & $30 \& 43$ & 0.01 & 8 & 6 & 2 & 2 & $2016 / 3 / 4$ & $\sqrt{ }$ & $x$ & $\sqrt{ }$ \\
\hline 6 & 6 & $2015 / 12 / 27$ & $28 \& 32$ & 1 & 3 & 1 & 0 & 0 & - & $x$ & $x$ & $x$ \\
\hline 7 & 7 & $2016 / 3 / 6$ & $30 \& 29$ & 0.01 & 9 & 5 & 2 & 1 & $2016 / 6 / 6$ & $\sqrt{ }$ & $x$ & $\sqrt{ }$ \\
\hline 8 & 8 & $2016 / 7 / 6$ & $32 \& 34$ & 19 & 7 & 2 & 0 & 0 & - & $x$ & $x$ & $x$ \\
\hline 9 & 9 & $2016 / 7 / 7$ & $35 \& 41$ & 12 & 4 & 0 & 0 & 0 & - & $x$ & $x$ & $x$ \\
\hline 10 & 10 & $2016 / 9 / 5$ & $34 \& 36$ & 3 & 7 & 3 & 3 & 0 & $2016 / 11 / 14$ & $\sqrt{ }$ & $x$ & $\sqrt{ }$ \\
\hline 11 & 11 & $2016 / 11 / 2$ & $38 \& 39$ & 3 & 11 & 6 & 3 & 0 & $2017 / 1 / 11$ & $\sqrt{ }$ & $x$ & $\sqrt{ }$ \\
\hline 12 & 12 & $2017 / 5 / 21$ & $26 \& 30$ & 0.5 & 17 & 4 & 0 & 2 & $2017 / 9 / 30$ & $\sqrt{ }$ & $x$ & $\sqrt{ }$ \\
\hline 13 & 13 & $2017 / 6 / 1$ & $29 \& 32$ & 0.05 & 9 & 2 & 1 & 0 & $2017 / 8 / 1$ & $\sqrt{ }$ & $\sqrt{ }$ & $x$ \\
\hline 14 & 14 & $2017 / 6 / 3$ & $32 \& 31$ & 0.1 & 10 & 3 & 2 & 0 & $2017 / 9 / 5$ & $\sqrt{ }$ & $x$ & $\sqrt{ }$ \\
\hline 15 & 15 & $2018 / 4 / 13$ & $37 \& 38$ & 1 & 6 & 3 & 0 & 1 & - & $x$ & $x$ & $x$ \\
\hline 15 & 16 & $2018 / 9 / 2$ & $37 \& 38$ & 0.01 & 7 & 4 & 0 & 1 & - & $x$ & $x$ & $x$ \\
\hline 15 & 17 & $2018 / 12 / 5$ & $37 \& 38$ & 0.1 & 9 & 4 & 0 & 4 & - & $x$ & $x$ & $x$ \\
\hline 16 & 18 & $2019 / 1 / 8$ & $32 \& 32$ & 2 & 9 & 6 & 1 & 2 & $2019 / 5 / 31$ & $\sqrt{ }$ & $x$ & $\sqrt{ }$ \\
\hline 17 & 19 & 2019/1/18 & $30 \& 29$ & 0.5 & 22 & 4 & 2 & 1 & 2019/4/17 & $\sqrt{ }$ & $x$ & $\sqrt{ }$ \\
\hline 18 & 20 & $2019 / 4 / 30$ & $36 \& 36$ & 1 & 3 & 1 & 0 & 1 & - & $x$ & $x$ & $x$ \\
\hline 18 & 21 & 2019/10/19 & $36 \& 37$ & 0.5 & 7 & 3 & 1 & 1 & - & $x$ & $x$ & $x$ \\
\hline 19 & 22 & $2019 / 5 / 29$ & $36 \& 36$ & 15 & 12 & 6 & 0 & 5 & - & $x$ & $x$ & $x$ \\
\hline 19 & 23 & $2019 / 8 / 27$ & $36 \& 36$ & 30 & 13 & 5 & 2 & 0 & $2019 / 10 / 29$ & $\sqrt{ }$ & $x$ & $\sqrt{ }$ \\
\hline 20 & 24 & $2019 / 6 / 26$ & $32 \& 27$ & 0.5 & 11 & 5 & 0 & 2 & - & $x$ & $x$ & $x$ \\
\hline 21 & 25 & $2019 / 9 / 20$ & $31 \& 33$ & 0.01 & 24 & 1 & 0 & 0 & - & $x$ & $x$ & $x$ \\
\hline 22 & 26 & $2019 / 10 / 2$ & $33 \& 32$ & 0.001 & 2 & 2 & 0 & 1 & - & $x$ & $x$ & $x$ \\
\hline
\end{tabular}

F: female; FF: female twins; M: male.

Among the 25 cycles, female euploid blastocysts were detected in 14 cycles, only male euploid blastocysts were detected in 8 cycles, and no euploid embryos were detected in the other 3 cycles. For the 14 cycles in which euploid female embryos were detected, euploid female blastocysts were transferred in 13 cycles, and one cycle was delayed due to coronavirus disease 2019 (COVID-19). For the 8 cycles in which only euploid male embryos were detected, one couple chose to transfer one male euploid blastocyst. The clinical pregnancy rate of 14 cycles of blastocyst implantation was $100 \%$. Finally, early abortion occurred in 2 cycles (abortion rate of $14.3 \%$ ), normal delivery occurred in 12 cycles (one cycle for monozygotic female twins, one cycle for males, and 10 cycles for females), and the live birth rate was $85.7 \%$ (Table 1 ).

\section{Discussion}

In this study, PGT-A was performed on ICSI embryos of AZFc microdeletion patients. Finally, the overall pregnancy rate and live birth rate were 100\% (14/14) and $86 \%(12 / 14)$, respectively, which were much higher than those in previous reports [13-15]. In fact, PGT-A should be carried out for ICSI embryos due to severe male factors to exclude aneuploid embryos [16]. However, PGT-A is commonly used in patients with severe male factors such as DANH1, PAG6 and others[17, 18], and PGT-A has not been reported in patients with AZF microdeletions.

Female age is a prominent factor affecting the outcome of ICSI-IVF $[19,20]$. However, male age had no significant effect on the rate of aneuploidy embryos [21]. The female age in this study ranged from 26 to 37, of which 16 were under 35 years old and 6 were over 35 years old. Among the 48 embryos under 35 years old, 28 (58.3\%) were aneuploid embryos (16 were female, and 12 were male). Among the 33 embryos over 35 years old, 20 (60.6\%) were aneuploid embryos ( 7 were female, and 13 were male). Overall, there was no significant correlation between aneuploidy frequency and female age, which may be because the eldest female age was 37 years old or the sample size was not large enough, and the influence on embryos was not prominent in this study. 
Male offspring of patients with AZF microdeletions using ART inherit AZF microdeletions, which may lead to similar or serious reproductive problems in adulthood [2-4]. In this study, after full genetic consultation with patients, for the 14 families who obtained female euploid embryos, most of them (13/14) chose to transfer female embryos, and one family was delayed due to COVID-19; for the 8 families who only obtained male euploid embryos, one family chose to enter the embryo transfer phase, and the other families chose to forgo embryo transfer.

Compared to ICSI using microTESE and ejaculatory sperm, the outcome of later sperm performed better [13, 14, 22]. In this study, our results show that PGT-A can significantly improve clinical outcomes after ICSI with ejaculated sperm in AZFc patients. However, the outcomes of PGT-A in AZFc patients undergoing ICSI with microTESE need further observation.

\section{Conclusions}

For patients with AZFc microdeletions, ICSI-IVF with ejaculatory spermatozoa and NGS-based PGT-A can significantly improve the chance of obtaining offspring.

\section{Patients And Methods}

\section{Patients and AZF microdeletion detection}

From 2015 to 2019, among the male patients who were diagnosed with AZFc microdeletion using a Y chromosome microdeletion detection kit (Tellgen, China) in the General Hospital of the PLA Northern Theater Command, 22 patients received assisted reproduction technologies (ART) with ICSI and PGT-A. The sperm concentration was evaluated according to the recommended method of the WHO Laboratory Manual for the Examination and Processing of Human Semen (5th edition). Twenty-six semen samples from 22 patients were analysed, and 25 semen samples were oligozoospermia ( $20 \mathrm{million} / \mathrm{mL})$, while the sperm concentration of the other semen samples was $\geq 20$ million $/ \mathrm{mL}$ (Table 1).

\section{Oocyte retrieval and oocyte insemination by ICSI}

The patients' wives received 11 days with daily infection of 150 IU recombinant follicle stimulating hormone (Merck Serono). On day $6,0.25$ mg gonadotropinreleasing hormone antagonist (Merck Serono) was given every daily until oocyte maturation by 4 mg of gonadotropin-releasing hormone agonist (triptorelin acetate for injection, Beijing Biote Pharmaceutical) on day 12. Thirty-six hours later, the oocytes were retrieved and cultured in Quinn's Advantage fertilization medium (Origio) at $37^{\circ} \mathrm{C}, 6.0 \% \mathrm{CO} 2,5 \% \mathrm{O} 2$ and $89 \% \mathrm{~N} 2$. For ICSI, cumulus cells were removed by using hyaluronidase (Origio) four hours after oocyte retrieval, and metaphase II oocytes were injected $5 \mathrm{~h}$ after retrieval.

\section{Quality assessment of fertilized embryos and blastocyst biopsy}

Fertilization status was assessed $18 \mathrm{~h}$ after ICSI, and normal fertilization was characterized by two distinct pronuclei and two polar bodies. The embryos developed to the blastocyst stage, and 5-10 trophoblastic cells were collected and transferred into $200-\mu \mathrm{L}$ sterile PCR tubes for PGT-A; the blastocysts after biopsy were cryopreserved for frozen embryo transfer.

A total of 5 - 10 trophoblast cells were used for whole genome amplification (WGA) according to the documentation of the SurePlex DNA Amplification System (Illumina, America), and WGA products were purified and recovered using AMPure XP beads (Beckman Coulter, America). The purified WGA products were used for library preparation using the VeriSeq ${ }^{\text {TM }}$ DNA Library Prep Kit (Illumina, America) and sequenced on the NextSeq 550 platform. The data were analysed by Peking Medriv Academy of Genetics and Reproduction.

Considering that sons of AZFc microdeletion patients will also inherit the affected Y chromosome [2-4], the patients were informed of not only the euploid condition but also the sex of the embryos. After full genetic consultation with the patients, the patients chose the embryo for implantation.

\section{List Of Abbreviations}

AZF: Azoospermia factor

ICSI: Intracytoplasmic sperm injection

IVF: In vitro fertilization

PGT-A: Preimplantation genetic testing for aneuploidies

ART: Assisted reproduction technologies

\section{Declarations}

\section{Ethics approval and consent to participate}


This research was approved by the Ethics Committee of General Hospital of Northern Theater Command. This was a retrospective study without any identifiers related to patients. All patients participating in the study provided informed consent.

\section{Consent for publication}

All patients in this study provided their consent for publication. A copy of the written consent is available for review by the Editor of this journal.

\section{Availability of data and material}

The datasets generated and analysed during the current study are not publicly available due to a concern to protect individual patient confidentiality, but are available from the corresponding authors on reasonable request.

\section{Competing interests}

The authors declare that they have no conflicts of interest.

\section{Funding}

This study was supported by the Family Planning Research Fund (19JSZ12). The funding body had no role in the design of the study; collection, analysis and interpretation of data; or in the writing of the manuscript.

\section{Authors' Contributions}

XW, FJ and YY designed the study. XW, YW, KH, DH, JZ, CT and WW performed the experiments. XW and YW drafted the manuscript. All authors reviewed and approved the manuscript.

\section{Acknowledgements}

We would like to thank all the patients and family members participating in this work for their cooperation and patience. We also thank the medical workers and other staff who have made efforts in this research.

\section{Authors' information}

Department of Reproductive Medicine, General Hospital of Northern Theater Command, Shenyang, 110000, China

Xiliang Wang, Kaibo Hou, Dongmei Hao, Jinyan Zhang, Chang Tan, Wei Wei, Yuexin Yu

Peking Medriv Academy of Genetics and Reproduction, Peking, 100000, China

Yankun Wang, Jia Fei

\section{References}

1. Lange J, Skaletsky H, van Daalen SK, Embry SL, Korver CM, Brown LG, Oates RD, Silber S, Repping S, Page DC, Isodicentric Y chromosomes and sex disorders as byproducts of homologous recombination that maintains palindromes. Cell, 2009; 138(5):855-69.

2. Kent-First MG, Kol S, Muallem A, Ofir R, Manor D, Blazer S, First N, Itskovitz-Eldor J, The incidence and possible relevance of Y-linked microdeletions in babies born after intracytoplasmic sperm injection and their infertile fathers. Mol Hum Reprod, 1996; 2(12):943-50.

3. Page DC, Silber S, Brown LG, Men with infertility caused by AZFc deletion can produce sons by intracytoplasmic sperm injection, but are likely to transmit the deletion and infertility. Hum Reprod, 1999; 14(7):1722-6.

4. Oates RD, Silber S, Brown LG, Page DC, Clinical characterization of 42 oligospermic or azoospermic men with microdeletion of the AZFc region of the Y chromosome, and of 18 children conceived via ICSI. Hum Reprod, 2002; 17(11):2813-24.

5. Racowsky C, Stern JE, Gibbons WE, Behr B, Pomeroy KO, Biggers JD, National collection of embryo morphology data into Society for Assisted Reproductive Technology Clinic Outcomes Reporting System: associations among day 3 cell number, fragmentation and blastomere asymmetry, and live birth rate. Fertil Steril, 2011; 95(6):1985-9.

6. Zhang HL, Zhao LM, Mao JM, Liu DF, Tang WH, Lin HC, Zhang L, Lian Y, Hong K, Jiang H, Sperm retrieval rates and clinical outcomes for patients with different causes of azoospermia who undergo microdissection testicular sperm extraction-intracytoplasmic sperm injection. Asian journal of andrology, 2021; 23(1):59-63

7. Niu X, Long J, Gong F, Wang W, Does ICSI for in vitro fertilization cause more aneuploid embryos? Mol Cytogenet, $2020 ; 13: 27$. 
8. Lathi RB, Milki AA, Rate of aneuploidy in miscarriages following in vitro fertilization and intracytoplasmic sperm injection. Fertil Steril, $2004 ; \mathbf{8 1}(5): 1270-2$.

9. Kushnir VA, Frattarelli JL, Aneuploidy in abortuses following IVF and ICSI. J Assist Reprod Genet, 2009; 26(2-3):93-7.

10. van Golde RJ, Wetzels AM, de Graaf R, Tuerlings JH, Braat DD, Kremer JA, Decreased fertilization rate and embryo quality after ICSI in oligozoospermic men with microdeletions in the azoospermia factor c region of the $Y$ chromosome. Hum Reprod, 2001; 16(2):289-92.

11. Colaco S, Sakkas D, Paternal factors contributing to embryo quality. J Assist Reprod Genet, 2018; 35(11):1953-68.

12. Kemper JM, Vollenhoven BJ, Talmor AJ, Preimplantation Genetic Testing for Aneuploidy: A Review. Obstet Gynecol Surv, 2019; 74(12):727-37.

13. Sabbaghian M, Mohseni Meybodi A, Rafaee A, Saba S, Zamanian M, Sadighi Gilani MA, Sperm retrieval rate and reproductive outcome of infertile men with azoospermia factor c deletion. Andrologia, 2018; 50(7):e13052.

14. Zhang HL, Zhao LM, Mao JM, Liu DF, Tang WH, Lin HC, Zhang L, Lian Y, Hong K, Jiang H, Sperm retrieval rates and clinical outcomes for patients with different causes of azoospermia who undergo microdissection testicular sperm extraction-intracytoplasmic sperm injection. Asian J Androl, 2021; 23(1):59-63.

15. Liu XY, Wang RX, Fu Y, Luo LL, Guo W, Liu RZ, Outcomes of intracytoplasmic sperm injection in oligozoospermic men with Y chromosome AZFb or AZFc microdeletions. Andrologia, 2017; 49(1):e12602.

16. De Rycke M, Vermeulen N, Moutou C, Meijer-Hoogeveen M, Rubio C, Kokkali G, Goossens V, Coonen E, Carvalho F, ESHRE PGT Consortium good practice recommendations for the organisation of PGT. Hum Reprod Open, 2020; 2020(3).

17. Wu H, Wang J, Cheng H, Gao Y, Liu W, Zhang Z, Jiang H, Li W, Zhu F, Lv M, Liu C, Tan Q, Zhang X, Wang C, Ni X, Chen Y, Song B, Zhou P, Wei Z, Zhang F, He $\mathrm{X}, \mathrm{Cao} \mathrm{Y}$, Patients with severe asthenoteratospermia carrying SPAG6 or RSPH3 mutations have a positive pregnancy outcome following intracytoplasmic sperm injection. J Assist Reprod Genet, 2020; 37(4):829-40.

18. Wambergue C, Zouari R, Fourati Ben Mustapha S, Martinez G, Devillard F, Hennebicq S, Satre V, Brouillet S, Halouani L, Marrakchi O, Makni M, Latrous H, Kharouf M, Amblard F, Arnoult C, Ray PF, Coutton C, Patients with multiple morphological abnormalities of the sperm flagella due to DNAH1 mutations have a good prognosis following intracytoplasmic sperm injection. Hum Reprod, 2016; 31(6):1164-72.

19. Franasiak JM, Forman EJ, Hong KH, Werner MD, Upham KM, Treff NR, Scott RT, Jr., The nature of aneuploidy with increasing age of the female partner: a review of 15,169 consecutive trophectoderm biopsies evaluated with comprehensive chromosomal screening. Fertil Steril, 2014; 101(3):656-63.e1.

20. La Marca A, Capuzzo M, Imbrogno MG, Donno V, Spedicato GA, Sacchi S, Minasi MG, Spinella F, Greco P, Fiorentino F, Greco E, The complex relationship between female age and embryo euploidy. Minerva Ginecol, 2020.

21. Dviri M, Madjunkova S, Koziarz A, Antes R, Abramov R, Mashiach J, Moskovtsev S, Kuznyetsova I, Librach C, Is there a correlation between paternal age and aneuploidy rate? An analysis of 3,118 embryos derived from young egg donors. Fertil Steril, 2020; 114(2):293-300.

22. Yamaguchi K, Ishikawa T, Mizuta S, Takeuchi T, Matsubayashi H, Kokeguchi S, Habara T, Ichioka K, Ohashi M, Okamoto S, Kawamura T, Kanto S, Taniguchi H, Tawara F, Hara T, Hibi H, Masuda H, Matsuyama T, Yoshida H, Clinical outcomes of microdissection testicular sperm extraction and intracytoplasmic sperm injection in Japanese men with Y chromosome microdeletions. Reprod Med Biol, 2020; 19(2):158-63. 